University of Louisville

ThinkIR: The University of Louisville's Institutional Repository

Faculty Scholarship

7-2015

Workplace dignity: Communicating inherent, earned, and remediated dignity

Kristen Lucas

University of Louisville, kristen.lucas@louisville.edu

Follow this and additional works at: https://ir.library.louisville.edu/faculty

Part of the Business Administration, Management, and Operations Commons, Organizational Behavior and Theory Commons, and the Organizational Communication Commons

Original Publication Information

Lucas, Kristen. "Workplace Dignity: Communicating Inherent, Earned, and Remediated Dignity." 2015.

Journal of Management Studies 52(5): 621-646.

This Article is brought to you for free and open access by ThinkIR: The University of Louisville's Institutional Repository. It has been accepted for inclusion in Faculty Scholarship by an authorized administrator of ThinkIR: The University of Louisville's Institutional Repository. For more information, please contact thinkir@louisville.edu. 
Journal of Management Studies 52:5 July 2015

doi: 10.1111/joms.12133

\title{
Workplace Dignity: Communicating Inherent, Earned, and Remediated Dignity
}

\section{Kristen Lucas}

University of Louisville

\begin{abstract}
Extant research on dignity at work has revealed conditions that contribute to indignity, employees' responses to dignity threats, and ways in which employees' inherent dignity is undermined. But while dignity - and specifically indignity - is theorized as a phenomenon subjectively experienced and judged by individuals, little research has privileged workers' own perspectives. In this study, working adults reveal how they personally experience and understand meanings of dignity at work. I describe three core components of workplace dignity and the communicative exchanges through which dignity desires commonly are affirmed or denied: inherent dignity as recognized by respectful interaction, earned dignity as recognized by messages of competence and contribution, and remediated dignity as recognized by social interactions and organizational practices that conceal the instrumental and unequal nature of work. Based on theoretical insights drawn from examining the relationships between these components, I argue that workplace dignity is a phenomenon theoretically distinct from human dignity.
\end{abstract}

Keywords: communication, competence, dignity, inequality, instrumentality, respect

\section{INTRODUCTION}

Dignity is a phenomenon that, at once, evokes deep desires and deep injuries. Its complexity and its salience in the human experience can be seen in the multiple ways it is described. In some cases, dignity is a psychological or cognitive outcome whereby people achieve a 'sense of' dignity. In this way, dignity may be experienced, felt, perceived, realized, pursued, or even lost or found. In other cases, dignity is a quality of interaction. People may or may not be treated with dignity, treat others with dignity, carry themselves with dignity, or act with dignity. In still other instances, dignity is something intrinsic to individuals; it is a vulnerable and valued part of their being. Dignity may be protected, defended, maintained, safeguarded, or taken back by the 
self. It may be respected or acknowledged, yet injured, violated, wounded, or denied by others. Regardless of whether it is considered an outcome, a quality of interaction, or the essence of one's humanity, dignity plays a role in how individuals experience and make sense of their place in the world.

One domain of life in which dignity plays a particularly salient role is the workplace, as it is a site where dignity can be both achieved and put at risk (Hodson, 2001; Sayer, 2007, 2011). To this point, Bolton (2007) maintains that dignity is a productive way to understand contemporary work, explaining that dignity 'encompasses issues that have exercised scholars of work for decades and offers a holistic lens through which workplace issues might be examined' (p. 7). However, this holistic lens is far from crystal clear. Despite management scholars long having used the word dignity when expressing concerns about work (Finlay et al., 1954; Garrison, 1952), they rarely have made dignity itself a focal point of attention or have defined it precisely (Bolton, 2013; see also Lee, 2008; Sayer, 2007). While dignity tends to be presented as a self-evident term that needs no explanation, conceptual clarity is essential for advancing research. Moreover, dignity is not just a scholarly term, but one that is personally significant for people in the workforce, as it is imbued with 'real world' meanings that reflect how dignity is experienced and understood. As such, greater knowledge of workers' perspectives can influence organizational efforts to foster dignity, as well as provide a basis for considering dignity implications of organizational practices, workplace encounters, and the like. Therefore, for purposes of both research and managerial practice, it is important to seek a full and robust understanding of dignity, particularly one that privileges workers' perspectives.

In this article, I present the results of a study examining the voices, meanings, and lived experiences of individuals regarding dignity at work. I identify three core dignity desires and the communicative exchanges through which those desires commonly are affirmed or denied - each of which I position as an essential component of workplace dignity. Based on theoretical interrogation of these components and the ways they intersect, I argue that workplace dignity is more complex than simply locating basic human dignity within a workplace context. Instead, workplace dignity is a phenomenon theoretically distinct from human dignity. In the next section, I situate the study by outlining theoretical foundations of workplace dignity and reviewing current empirical research.

\section{WORKPLACE DIGNITY}

\section{Theoretical Foundations}

Dignity generally is defined a personal sense of worth, value, respect, or esteem that is derived from one's humanity and individual social position; as well as being treated respectfully by others (Hodson, 2001; Lee, 2008). There are four core theoretical foundations of workplace dignity that are of particular import for understanding dignity in workplace contexts, and which collectively undergird the growing body of empirical research on workplace dignity. The first foundation is that there are two distinct meanings to dignity: inherent dignity and earned dignity. Inherent dignity is the 
belief in an unconditional god-given dignity, whereby all people have an intrinsic and equal value simply as a consequence of being human (Brennan and Lo, 2007; Dierksmeier, 2011). This meaning is sometimes referred to simply as 'human dignity'. Notably, the depiction of dignity being god-given is made independent of any particular religious tradition; instead, it references more broadly the conviction that human value is absolute and accorded to all without exception. In fact, Brennan and Lo (2007) maintain that secular and religious conceptions of human dignity are highly compatible as secular underpinnings carry an 'ethical residue of the traditional religious world view' of god-granted dignity (p. 49). Earned dignity is a belief that dignity is conditional; due to differential qualities, abilities, and efforts, some individuals will secure for themselves greater dignity and privileges than others (Brennan and Lo, 2007). In this sense, dignity is meritocratic and self-generated. Particularly in workplace contexts, earned dignity is linked to value and esteem that comes from performing work (Castel, 1996) and deriving self-value from instrumental contributions (Islam, 2012; Sayer, 2009). These two meanings offer different routes to achieving dignity at work or, alternatively, different routes by which dignity pursuits can be blocked.

The second foundation is that dignity is subjectively experienced and judged by the individual. Lee (2008) explains, 'the starting point [of dignity] is either an individual's or a group's own perception as opposed to that of an outsider's' (p. 8, emphasis added). To say dignity is subjectively experienced and judged is not to say it cannot be vicariously experienced or externally judged. Nor is it to say dignity is experienced in a vacuum. Individuals may apply commonly-held standards of interaction to make judgments about the dignity of others, they may feel emotionally aroused or called to action by witnessing the indignities of others, or they may compare themselves against societal standards and/or salient others to arrive at a sense of what is acceptable (Sayer, 2011). Ultimately then, what it means to say that dignity is subjective is that it is a deeply personal experience and the ultimate arbiter of dignity affirmations and denials is the individual and not 'objective' outsiders.

The third foundation is that dignity is inextricably tied to normative expectations, as evidenced in its roots in Christian theology (Brennan and Lo, 2007; Tablan, 2015), Kantian philosophy (Sayer, 2007), and business ethics (Dierksmeier, 2011). Specifically, there is a moral imperative that dignity will be upheld and, therefore, all violations are deemed to be problematic. This normative perspective dovetails with the fourth foundation, namely that the nature of the employment relationship is frequently at odds with achieving dignity. On the one hand, employment is a social relationship that holds promise for contributing positively to one's identity, self-esteem, and flourishing; on the other, it is an economic exchange relationship organized by structures of power and control that constrain agency, heighten risks of exploitation, and potentially dehumanize workers (Belanger and Edwards, 2013; Bolton and Laaser, 2013; Sayer, 2007; Thompson, 2013). Given the normative expectations of dignity, the economic exchange basis of the employment relationship becomes a central focus of understanding how workplaces are organized and, in turn, how dignity is experienced and/or violated at work.

For instance, one key concern arising from the economic exchange relationship is that workplaces are instrumentally-driven. The very nature of the employment 
relationship is one where people are hired as an means to an end, which runs counter to the belief that people should be treated as ends unto themselves (Sayer, 2007, 2011). Workplace instrumentalities are evidenced in several ways: employees are viewed as narrowly delimited role occupants, assumed to have no other interests or priorities than work, positioned as readily replaceable by someone or something that serves the organization better, and regarded as 'bundles of human capital rather than as conscious, freely choosing agents' (Islam, 2012, p. 237; Karlsson, 2012). Another concern is that workplaces are rife with inequalities - from unequal distribution of material rewards, to asymmetrical power relationships and rules of interaction, to limitations on opportunities to engage in meaningful work, to disproportionately allocated space (privacy, safety, and comfort), and more (Lucas and Gist, 2015). These inequalities can influence respectful treatment, autonomy, and other key indicators of dignity (Sayer, 2007, 2011), as well as limit individuals' agency in defending themselves in the face of dignity threats (Newman, 1999). It is within these instrumental and unequal contexts that people's dignity frequently is violated, as is evidenced by numerous empirical studies.

\section{Empirical Contributions}

At the outset, it is important to note that workplace dignity is conceptually related to, but distinct from, several other prominent lines of organizational research that broadly address issues of human flourishing at work. For instance, with regard to self-worth, dignity overlaps with research on meaningful work as a source of self-worth (Dempsey and Sanders, 2010), dirty work and occupational stigma as detractors (Ashforth et al., 2007), and organizationbased self-esteem as one's overall sense of being capable, significant, and worthy as an organizational member (Pierce and Gardner, 2004). With regard to being treated respectfully, there are strong connections to research on disrespect and communicative behaviours that may lead to injuries or denials of dignity, such as incivility (Pearson and Porath, 2005), workplace bullying (Lutgen-Sandvik et al., 2007), and abusive supervision (Tepper et al., 2007). Finally, because of its moral and ethical undercurrents, it is related to research on organizational justice, especially interpersonal justice (Patient and Skarlicki, 2010). Each of these areas has its own impressive corpus of work. In this article, however, I attend only to studies that explicitly address dignity.

Empirical research has made important contributions to understanding dignity, as well as problems of work and workplaces. The primary contributions of this research can be seen in two overlapping themes. The first theme of dignity research is that it centres on violations of dignity - which is to be expected given its normative theoretical foundation. To begin, research has highlighted various conditions that threaten dignity. For instance, Hodson (2001) identified four primary factors: overwork, mismanagement and abuse, incursions on autonomy, and paradoxes of participation (see also Lucas et al., 2013). Other studies have identified more specific contributors to indignity: verbal abuse and humiliation (Khademi et al., 2012; Stuesse, 2010), stigma attached to certain kinds of work (Chiappetta-Swanson, 2005) and workplaces (Otis, 2008), being compelled to demonstrate servility to others (Kensbock et al., 2014), implementation of 
coercive controls that dehumanize workers and erode pride (Crowley, 2012), and callousness and a lack of care while communicating about job loss (Gunn, 2011).

Likewise, research has provided insights into how employees respond to dignity threats. One type of response is engaging in identity work to create a positive and distinctive sense of self. This research includes reframing stigmatized dirty work to focus on positive attributes of the job (Chiappetta-Swanson, 2005; Stacey, 2005) to positioning oneself in comparison to others in order to make a claim for dignity (Lucas, 2011; Purser, 2009). Another response to dignity threats is engaging in resistance, such as absenteeism, labour organizing, striking, sabotage, and quitting (Cleaveland, 2005; Hodson, 2001; Roscigno and Hodson, 2004; Stuesse, 2010). Resistance to indignity also has been shown to be: subtle, such as cynicism communicated by employees rejecting offensive organizational cultures (Fleming, 2005); productive, such as advocacy and organizing efforts by LGBTQ employees experiencing dignity threats due to sexual orientation and/or gender expression (Baker, 2014); and creative, such as the myriad tactics captured in a collection of organizational misbehaviour narratives (e.g., wearing ugly ties to resist a company dress code; Karlsson, 2012).

A second theme of empirical research is that it has focused almost exclusively on ways inherent dignity is threatened in the workplace. In addition to the inherent dignity denials described above, research has highlighted specific problems of dehumanization and reification. Dehumanization occurs when people are treated as sub-human. For instance, aspiring professional athletes who navigated the National Football League's recruiting system were subjected to a battery of invasive medical examinations, communicated with and about in demeaning and dehumanizing ways, and poked and prodded in a manner that was likened to the 'slave trade' and 'meat market' (Dufur and Feinberg, 2007). Similarly, fashion models endured rejections, brutal and sexualized criticism, and intentional humiliations that reduced them to 'paper dolls' (Mears and Finlay, 2005). Reification occurs when people are treated as bundles of human resources that are replaceable, expendable, and disposable, instead of as human beings who have value that transcends the workplace. For instance, the Dilbert comic strip is a widely popular representation of cubicle life, in which a recurring theme is management treating employees like 'exploitable commodities' (Doherty, 2011). In a meatpacking plant, immigrant workers were made to feel worthless when a supervisor had told them to their faces that they 'aren't worth more than a bunch of disposable cups or disposable plates that you use and toss in the garbage' (Apostolidis, 2005, p. 650).

\section{Summary and Research Questions}

In summary, empirical research has provided important insights into a range of conditions that contribute to indignity, examined how employees respond to dignity threats, and described how employees' inherent dignity is undermined by dehumanization and reification. However, critical gaps remain. Namely, while there has been much gained in terms of understanding indignity at work, there is very little understanding of dignity as a positive experience. Moreover, empirical research has tended to neglect its theoretical foundation of dignity being subjectively understood. While researchers tend to take the position of and be sympathetic to workers, rarely have researchers directly 
and explicitly asked individuals about their experiences or judgments of dignity. In fact, Bolton (2010) says, 'to date there are only limited available insights into what dignity at work might mean to workers and managers in their day-to-day working lives [and] how this impacts upon their experiences of work' (p. 161). Instead, dignity research tends to draw upon researchers' a priori assumptions, retrospective interpretations, and/or outsider judgments of dignity (for exceptions, see Baker, 2014; Khademi et al., 2012; Lucas, 2011). While researcher-centred interpretations may indeed reflect judgments consistent with workers' lived experience, much more needs to be done to privilege subjective meanings to gain a full sense of the meanings and experiences of both indignity and dignity in workers' lives as they navigate the instrumental and unequal world of work. Therefore, I pose the following research questions:

Research Question 1: How do employees understand and experience affirmations and denials of workplace dignity?

Research Question 2: How do these lay understandings inform our theoretical understanding of workplace dignity?

\section{METHOD}

The purpose of this study was to gain theoretical insight into workplace dignity, particularly as it is subjectively experienced. Therefore, I was guided by an interpretivist research approach. The goal of interpretivist research is to seek understanding of human action, motives, feelings, experiences, and sensemaking from the perspective of organizational members (Gioia and Pitre, 1990; Lindlof and Taylor, 2011). Moreover, due to problems that arise from indignity, such as meaninglessness, illegitimacy, and quality of work-life, interpretivist approaches were particularly appropriate (Alvesson and Deetz, 2000).

I recruited participants by placing classified ads in the Help Wanted section of a local newspaper and posting flyers on community bulletin boards throughout a midsized midwestern US city. Participants included 62 adults who worked in service industries (40 per cent; food service, customer service, hospitality), blue-collar occupations (22 per cent; assembly work, construction, painting); professions (22 per cent; education, social work, engineering, accounting and finance); and sales (16 per cent; telephone sales, direct sales, retail). They were evenly divided by sex (31 women, 31 men), with an average age of 42 . The racial breakdown of the group was white (82 per cent), African American ( 8 per cent), Native American ( 5 per cent), and multi-racial (5 per cent), which was slightly more diverse than the city population as a whole. The 14 focus groups ranged in size from 3 to 8 , with a median size of 5 . I offered participants a small cash payment to compensate for their time. Additionally, I held focus groups at various days and times (including late mornings, evenings, and weekends) to enable people working different shifts to participate.

Interpretivist research favours data collection tactics which allow participant meanings to guide research (Creswell, 2007). While there are several specific techniques 
that meet this objective (e.g., interviews, ethnography), I chose focus groups as the method of data collection for several reasons (Kamberelis and Dimitriadis, 2005; Morgan, 1997). First, focus groups are an efficient way to gather information on a specific topic (as compared, for example, to participant-observation). Second, focus groups provide a valuable source of insights into complex behaviours and motivations, as participants engage in synergistic processes of sharing and comparing as they converse with one another. Third, focus groups are particularly well-suited to topics that typically may not be considered in much detail. While workplace dignity can be a complex and emotionally-laden phenomenon, it also is likely that it is not something people regularly discuss - at least at an abstract level. Fourth, focus groups decentre the role of the researcher, which allows for participants to take greater ownership over the flow of content and construction of collective and multivocal meanings. Therefore, focus groups were an ideal way to learn about diverse participants' experiences of dignity.

I designed the focus group protocol to delve into concrete experiences rather than more abstract understandings. As such, I asked participants three main questions: (1) What is the first thing you think of when you hear the term 'workplace dignity'?(2) Describe a time at work when you felt you experienced dignity; and (3) Describe an experience at work when you felt you did not have dignity. This simplified line of questioning was designed to discern a lay understanding that is informed by lived experiences. Furthermore, I encouraged participants to engage in conversation with one another, rather than to respond to questions in round-robin fashion. I intervened only to redirect conversation when it got off topic or to ask occasional follow-up questions (e.g., 'What do you mean by that?' 'Can you give an example?'). I did not prompt participants to give responses of any particular type. Most follow-up questions were posed by participants as they engaged in conversation with others in the group. To conclude each session, participants collaborated with one another to produce a list of 'rules' organizations could follow to provide more dignity for employees.

Focus groups were audio-recorded and a research assistant took notes throughout. The recorded portions of the sessions totalled 15 hours of talk, for an average of approximately one hour each. Recordings were transcribed by a professional transcription service. Research assistants verified the transcripts against the original recordings. They also concealed names and other personally identifying information of each participant. In total, there were 271 pages of single-spaced transcripts.

Data analysis occurred inductively. I began with primary-cycle coding, in which I analysed data to identify emergent patterns and meaningful categorizations (Tracy, 2013). This process started with line-by-line coding (Lindlof and Taylor, 2011). The goal was to privilege words and meanings forwarded by participants. For instance, initial coding included 'looked down upon', 'chewed out', and 'invisible'. Additionally, by using qualitative data analysis software, I was able to mark passages with multiple codes. Therefore, I simultaneously coded for key aspects of experiences, such as indicating who was involved in an interaction (e.g., 'customer', 'boss', 'coworker'), identifying responses (e.g., 'quitting', 'standing up for self'), signalling emotional reactions ('sad', 'frustrated', 'proud'), and reflecting theoretical concepts that were invoked but not explicitly stated by participants (e.g., 'dirty work' to tag a story told about working 
in a sewer, or 'power' to indicate abuses and imbalances of power). I coded approximately 500 utterances (e.g., quotations, narratives, short dialogues) with more than 200 unique codes. As a next step, I hierarchically-clustered codes to identify major categories of factors leading to dignity and indignity (Miles et al., 2014; Tracy, 2013). In this process, I streamlined first-order codes (e.g., 'thank you' and 'appreciation' were collapsed into a single code) and then grouped codes into larger conceptual categories, or 'code-families', that were the basis of the primary themes. For instance, 'working beneath skill level', 'training', 'highlighting mistakes', and similar concepts were grouped as a code-family of 'competence'.

From there, I revisited the transcripts for secondary-cycle coding to facilitate deeper interpretation. In this stage, the purpose of coding was to explain, theorize, and synthesize emergent categories at a more abstract level (Tracy, 2013). For example, I coded whether each incident had a positive or negative effect on dignity (e.g., a story about expertise being recognized was coded as 'affirmation'; one about expertise being disregarded was coded as 'denial'). With this additional coding in place, I was able to generate several 'super-codes' to identify passages coded with both a code-family code and either 'affirmation' or 'denial' (e.g., 'respectful interaction + affirmation' or 'respectful interaction + denial'). I then built data matrices that displayed exemplars of the super-codes. These matrices presented data in a more accessible and aggregated manner, which enabled me to summarize themes, recognize patterns in the data, examine underlying relationships, and draw inferences. For instance, 'respectful interaction' almost always was experienced as a denial of dignity; 'competence' was experienced equally as a denial and an affirmation. Throughout the process of iterative immersion to test relationships between data and theory (Tracy, 2013), I returned several times to processes of secondary-cycle coding and building data matrices as a way to examine and refine my findings. In some cases, I linked initially separate codes (e.g., combining 'competence' and 'contribution' into a single code-family), while at other times I split initially integrated codes into theoretically unique concepts (e.g., separating remediated-instrumentality from remediated-inequality). As is generally the case with inductive analysis, the process was more messy and circuitous than linear (see Tracy, 2012). The resulting themes are presented below.

\section{EARNED, INHERENT, AND REMEDIATED DIGNITY}

Participants' explanations and stories of dignity coalesced around three central themes, all of which were grounded in concrete experiences and interactions with others. The themes represent specific dignity desires and the communicative exchanges that commonly affirm and deny those desires. Additionally, they illustrate three distinct components of dignity. By components, I refer to parts that work together to achieve an overall effect. These components include: (1) inherent dignity as recognized by respectful interaction; (2) earned dignity as recognized messages of competence and contribution; and (3) remediated dignity as recognized by social interactions and organizational practices that conceal workplace injuries. Below, I describe each component, explaining its defining characteristics and illustrating it with participants' perspectives and experiences. See Table I for a summary. Ultimately, 
Table I. Summary of workplace dignity components

\begin{tabular}{|c|c|c|c|c|}
\hline & & & \multicolumn{2}{|c|}{ Remediated dignity } \\
\hline & Inherent dignity & Earned dignity & Instrumentality & Inequality \\
\hline Basis of value & $\begin{array}{l}\text { Intrinsic value as } \\
\text { a human being; } \\
\text { unconditional }\end{array}$ & $\begin{array}{l}\text { Instrumental } \\
\text { value based on } \\
\text { contribution to } \\
\text { organization; } \\
\text { conditional } \\
\end{array}$ & $\begin{array}{l}\text { Undermined value } \\
\text { due to } \\
\text { instrumental } \\
\text { nature of work } \\
\text { relationship }\end{array}$ & $\begin{array}{l}\text { Undermined } \\
\text { value due to } \\
\text { inequalities } \\
\text { embedded in the } \\
\text { workplace } \\
\end{array}$ \\
\hline Valence & Positive & Positive & Negative & Negative \\
\hline Position & $\begin{array}{l}\text { Entitled; } \\
\text { automatic, } \\
\text { maximum value }\end{array}$ & $\begin{array}{l}\text { Expected; varied } \\
\text { value based on } \\
\text { ability, effort, etc. }\end{array}$ & $\begin{array}{l}\text { Injured; } \\
\text { intermittent } \\
\text { salience based on } \\
\text { presence/visibility } \\
\text { of injuries due to } \\
\text { instrumental-only } \\
\text { valuation }\end{array}$ & $\begin{array}{l}\text { Injured; varied } \\
\text { depth of injury } \\
\text { based on } \\
\text { relative } \\
\text { positionality to } \\
\text { referent others }\end{array}$ \\
\hline Affirmations & $\begin{array}{l}\text { Respectful } \\
\text { interaction, } \\
\text { politeness, civility }\end{array}$ & $\begin{array}{l}\text { Acknowledgement } \\
\text { of competence } \\
\text { and contribution, } \\
\text { praise, } \\
\text { compliments }\end{array}$ & $\begin{array}{l}\text { Treatment as a } \\
\text { unique individual, } \\
\text { expressing } \\
\text { interest beyond } \\
\text { immediate work } \\
\text { role, initiating } \\
\text { interaction or } \\
\text { offering care with } \\
\text { expectation of } \\
\text { instrumental } \\
\text { exchange }\end{array}$ & $\begin{array}{l}\text { Parity in forms } \\
\text { of naming or } \\
\text { treatment, } \\
\text { inclusion, } \\
\text { references to } \\
\text { 'team' } \\
\text { membership }\end{array}$ \\
\hline Denials & $\begin{array}{l}\text { Disrespectful } \\
\text { interaction, } \\
\text { rudeness, abuse }\end{array}$ & $\begin{array}{l}\text { Insults, public } \\
\text { reprimands, } \\
\text { denials of } \\
\text { contribution }\end{array}$ & $\begin{array}{l}\text { Treatment as an } \\
\text { object, callousness } \\
\text { or insensitivity in } \\
\text { severing } \\
\text { employment } \\
\text { relationship, } \\
\text { exploiting } \\
\text { expendability as a } \\
\text { means of control }\end{array}$ & $\begin{array}{l}\text { Calling attention } \\
\text { to status } \\
\text { differences, } \\
\text { differential } \\
\text { treatment based } \\
\text { on status, } \\
\text { exclusion or } \\
\text { treatment as } \\
\text { invisible }\end{array}$ \\
\hline
\end{tabular}

these components and the relationships between them suggest that workplace dignity is a phenomenon theoretically distinct from human dignity.

\section{Inherent Dignity as Recognized by Respectful Interaction}

The first theme that surfaced in participants' stories was a desire for respectful interaction, which was closely linked to inherent dignity. In response to the opening query, 'what is the first thing you think of when you hear the term workplace dignity?' the majority of participants simply said 'respect' and then elaborated on their understanding of dignity as 'a basic level of respect based on being a human being' and, more succinctly, 'being treated like a human being'. For participants, being treated as a 
human being encompassed a sense of general respect dictated by social conventions of civility: politeness, proper forms of address, greetings, and so forth. Participants wanted their interactions with bosses, peers, customers, and other job-salient others to reflect the same quality of respect that would be afforded to others as a matter of common courtesy. But when it came to concrete experiences, few recalled specific incidents when they felt dignified by 'basic respect'. Even when pressed for more detail, answers were vague. A security guard said he had several jobs 'where they treated me real well, with dignity and respect'. But when asked what his boss and coworkers specifically did in those circumstances that made him feel dignified, he explained, 'they just treated you with respect and made you feel like you were a person and not a machine'.

Unsurprisingly, there were many more denials than affirmations of people's desire for respectful interaction. In contrast to affirmations, denials were recalled in great number, in great detail, and with great intensity. Experiences of disrespect included but were not limited to being ignored, interrupted, cussed at, yelled at, ostracized, called names, bullied, and physically struck. As suggested by the contrast offered above (feeling like a person instead of a machine), participants described with strong emotion ranging from sadness to frustration to outright anger - the indignity of being treated in ways less than human, whether it was like inanimate objects ('number', 'robot'), animals ('monkey', 'little puppy'), or simply invisible ('a nobody'). Even relatively innocuous disrespect was considered to be a denial of one's humanity and inherent dignity. For example, a blue-collar labourer explained his frustration with being ignored as he received his orders for each day:

I'm standing, I'm like, we're all in the same room. But the whole time [the boss] just started talking to the other guy. It was just like not even acknowledging me, you know? 'And let your guy know this, and let your guy know that'. And I'm like, 'his guy is standing right here'. I just felt like that was just degrading, on a personal level, professional level, just every level, just all the way around.

When disrespect was perceived to have a hostile intent, denials of dignity were even more intensely experienced. In one of the more egregious examples - but not a completely isolated occurrence with regard to its intensity - a restaurant supervisor suffered verbal abuse and name calling at the hands of his general manager:

He started like using racial terms towards me, cracking chubby jokes. And it kind of trickled down to all the other employees. And so I got less respect from the rest of my employees. When I was managing, it got to a point to where sometimes they didn't want to listen to me because of what they had seen from him doing to me. He would always try to belittle me, it seemed like. All the other people, whenever there was a huge crowd of employees or meetings or something, he would always like try to do something to make me feel bad.

In this case, the supervisor not only was subjected to disrespectful interaction from his manager, but his inherent dignity was further undermined when the abuse created 
a domino effect of lack of respect from the crew who reported to him. As he described with raw emotion the cumulative effect of the disrespect on his confidence and self-worth, another participant empathized with him saying, 'I don't know why people are that way, that they break you down, down, down, make you sick'.

In summary, the desire for respectful interaction is inextricably tied to inherent dignity. As previously explained, inherent dignity is based on a belief all individuals are entitled to dignity for the sake of being human. This component was clearly, explicitly, and repeatedly articulated by participants. The prominence of denials and the near-absence of affirmations of respectful interaction further attest to the belief that people are entitled to inherent dignity. That is, it was fully expected that organizational others (supervisors, coworkers, customers, etc.) would recognize the inherent worth of individuals as equal to all others and acknowledge it through respectful interaction. When people were treated respectfully, no dignity reactions were triggered because their expectations were met; that is why there were so few clear memories of times when people were treated with dignity. But when they were treated disrespectfully, there were immediate judgments - even for innocuous events - that their dignity had been violated.

\section{Earned Dignity as Recognized by Messages of Competence and Contribution}

The second theme that surfaced in participants' stories was a desire to be recognized for instrumental contributions to the organization. This desire was associated with earned dignity. At a basic level, all participants expressed the sentiment that every job - no matter where it is located in an organizational hierarchy - provides instrumental value.

Furthermore, as people worked harder in their respective roles and/or met or exceeded quality standards, they had an expectation of greater instrumental value. Affirmations of earned dignity centred on messages relating to competence and contribution, including messages that acknowledge skill, ability, special accomplishment, and/or effort and expertise required to perform a job. Specific examples included praise, compliments, appreciation for work well done, trust in one's abilities and judgment, appreciation for contribution to the workgroup or organization, explicit acknowledgement of the job role's importance to the organization, and affirmation of the position's value to society at large. Denials included messages that disregard or call into question ability, effort, and expertise. Examples included insults about one's job role, highlighting mistakes, and issuing public reprimands.

A key way that the centrality of competence to workplace dignity was articulated was through the excitement conveyed when people talked about doing an excellent job, accomplishing something others could not, or taking on additional responsibilities that went above and beyond routine duties. These stories ran the gamut from a janitor who mopped floors, to an optician who carefully and correctly filled prescriptions, to a nursing home cook who was responsible for preparing meals for 100 residents with a variety of dietary restrictions, to an aide who researched and wrote Congressional speeches. The range of occupations in which people talked about competence and contribution demonstrated that earned dignity is not reserved only for high-skilled employees, but is important to everyone. 
Even more dignifying than doing a job well was to do it well and be recognized by others for the quality of that contribution. Even when recognition was a token gesture, the affirming effect often was strong. A retail cashier who had the task of asking customers if they wanted to make a donation to a charity was given a 'little rose' by her manager, which made her 'feel like I was worth something'. A fast food worker who was scheduled to be one of three cooks on an especially busy day ended up working alone when 'two of them bailed out'. He beamed with pride as he described what ensued:

I ran the kitchen from 2:30 in the afternoon until probably about 9:30 at night by myself. I think they said that night grossed probably like about $\$ 10,500$ where I cooked by myself. You know what I'm saying? There wasn't no backup. Nobody had to wait for nothing. Everybody got what they wanted when they wanted it.

His accomplishment, which demonstrated his competence in performing well under pressure and his contribution to the organization, was further bolstered when his efforts were praised by his manager:

Later that night when we shut down, everybody shut down the place, our manager went out, got pizza, pop, everything, got everything. And he just pretty much told me I did a good job, keeping up with doing everything. And we had like a little party at the end of the night. So that kind of picked me up. I was ready to throw in the towel there for a while, but I fought through it, got it done, and at the end of the night it was almost like didn't even notice. I didn't mind coming to work after that, you know.

Of course, the converse is true of indignity. When people's instrumental value was challenged through verbal threats of their competence, indignity ensued. Making evaluative comments about people's ability to perform the job was strongly tied to earned dignity. In the situation below, a secretary described how her manager repeatedly mentioned a onetime mistake (perhaps thinking it simply was a joke), but overlooked giving praise for all the times her job was performed competently:

We make ballots for voting. And one time I forgot to change the date on the ballot. And I'd done it like 50 times fine. One time I forgot to change the date. So now, every time we do that, my boss goes, 'Don't forget to change the date'. That makes me feel like, 'how about the other 50 times I did it right?' And then the one time that I goofed it up, he keeps bringing that up. 'Did you change the date?' It makes you feel like he thinks you're an idiot, you know.

In addition to highlighting mistakes, there were other ways instrumental value was violated. One common way was when workers' contributions went unacknowledged. For instance, a night-shift employee who was responsible for stocking a large discount store complained about the lack of recognition she experienced in comparison to day-shift workers: 
The blame always falls on us [the overnight crew], because we're the ones that receive all the goods in. If they don't get out to the floor, then we're the ones that always get stuck with the blame. The day shift gets a lot of, 'we appreciate your help doing this and this and that', and you hardly ever hear the night shift getting, 'we appreciate you working your butts off to get this put out'... . It's really a tough job. I don't think people realize all the work that goes into it.

The stocker possessed a strong sense of the contribution she makes to her organization. While she recognized her own competence and contribution, the violation of her dignity occurred when her manager did not acknowledge those efforts. She continued:

It's just like, okay, do you really realize, I mean, the whole spectrum of what I really do for you guys? I probably do 16 hours worth of work in 8 hours. Where's my 'thank you'? Where's my 'you did such a good job'? Can I just break my own arm and pat myself on the back?

A unique quality of the earned dignity component is that workers have an expectation of how much instrumental value they provide to their respective organizations. At this level, it is not about everyone being entitled to the same amount of dignity - but instead that greater contributions generate greater dignity. While some instrumental worth is accumulated through internal satisfaction (e.g., employees knowing they have performed a job well), it is essential that their instrumental value is acknowledged by salient organizational others.

In summary, the need for recognition of competence and contribution is an essential part of the earned dignity component. Unlike inherent dignity, in which individuals feel entitled to an unconditional valuation of their worth, earned dignity is conditional and varied. On the one hand, participants indicated they possess a clear sense of their competence and contribution. But on the other hand, simply being competent (e.g., demonstrating job-specific knowledge, executing a job well) was not enough. Dignity was dependent, in part, upon symbolic acts of others recognizing their competence and contribution in order to build or maintain a sense of self-worth and self-esteem as related to their particular job role. As such, they expected that their contributions would be acknowledged by organizational others at an appropriate level to their own contribution whether that was through praise, appreciation, or even freedom from micromanagement. When messages of competence and contribution exceeded their perceived instrumental contribution to the organization, positive dignity reactions were triggered; when those messages fell short (or worse yet, undermined their competence and contribution), indignity reactions were triggered.

\section{Remediated Dignity as Recognized by Messages that Conceal Workplace Injuries}

The third theme that surfaced in participants' stories was a desire for and dependence upon others to remedy (or at least not further exacerbate) workplace injuries of 
instrumentality and inequality. This dignity desire is the core of a third component of dignity, which I term 'remediated dignity'. Unlike the previous two components that share a positive expectation for dignity, remediated dignity starts from a negative position. People (especially those who work in lower hierarchical positions or whose employment situations are more precarious) tend to be acutely aware of, if not resigned to, the instrumentality and inequality of their workplaces. Even though they may accept conditions of instrumentality and inequality as a reality of working life, their resignation does not mitigate dignity injuries. As such, remediated dignity calls for repair and restoration of an injured value. In this regard, individuals are dependent upon others to limit injuries and protect their sense of dignity. Affirmations of dignity came in the form of social interactions and organizational practices (i.e., ordinary workplace activities and ways of doing things, such as policies, behaviours, rules, or customs) that conceal the instrumental and unequal nature of work. In contrast, denials of dignity came in the form of social interactions and organizational practices that reveal the instrumental and unequal nature of work. These latter exchanges were particularly devastating as they were perceived as adding insult to injury. Because of nuances between injuries caused by instrumentality and those caused by inequality, remediated dignity is composed of two subtypes.

Remediation of instrumental-only valuation. The first workplace injury that requires remediation is when people are valued only for their instrumental worth. While participants fully recognized that they were employed for the purpose of completing an instrumental task - and, by and large, accepted that reality - they did not willingly accept that their entire value is reducible to their instrumental contributions. Instead, they expressed a strong desire to be valued as a whole person who is intrinsically deserving of respect, who also holds an instrumental role. Put into practice, people wanted to be recognized as a unique individual who is neither readily interchangeable with another nor treated as a cog in a machine. For instance, a grocery store employee talked animatedly about the satisfaction he received from being introduced as a special member of the organization:

When I first started working, we had 50 people at this conference and [the general manager] gets up and introduces me, and said 'I'm so glad to have this person on'... It was amazing. I mean, you're willing to work for someone like that who really appreciates what you do. He knew how to treat employees to make them do good and want to work for him. It's big, because you want to be appreciated.

In contrast, employees were frustrated and felt their inherent value was denied by exchanges that highlighted their expendability. A blue-collar labourer who worked for 11 years at a small company was terminated with little notice or explanation:

I guess they decided they needed to downsize or whatever, and they gave me like about 10 minutes notice and just on a Friday they said, 'Well, you're laid off'. I tried to ask questions. Well, for how long and stuff like that, and it was, 'I don't know. I don't know. I don't know'. But I knew that it wasn't really a layoff. They 
was just actually terminating me. They just was telling me that I was laid off and then a few days later, when I was at home, I got a letter in the mail that said your temporary layoff is permanent now. I knew that when they was saying that I was just laid off. I just wanted to get them to admit it, and they wouldn't admit it. And, you know, that wasn't treating me with very much dignity there. I was there like 11 years and you would think being a loyal employee for 11 years they would give you a little more than 10 minutes to tell you you're gone.

In this example, the employee believed he was deserving of more respectful interaction because of his years of service, but instead was treated simply as someone (or perhaps something) disposable when he no longer was needed. While he may have accepted he was not valued beyond his instrumental role with the company, the impersonal way in which he was terminated added insult to the injury of being expendable.

In a dramatic case, another person got choked up as he described his employer's disregard for his and his coworkers' inherent worth. In addition to his primary role in a manufacturing plant, he also served as the company's safety warden. When an emergency arose and he attempted to help workers seek safe shelter, he was given a different instruction by management:

One day the tornado sirens go off. I said, 'Well, everyone knows where to go'. And I get this phone call. 'Nah, it'll be all right. Just keep going'. 'What are you talking about? Keep it going? There's a tornado right across the highway down a block'. They said, 'Ah, just keep it - Well, just go out there and keep your eye on it'.... I've seen a lot of dangerous things, but that was such lack of respect for human life that [trails off]. It was just awful. I'm still thinking about it, getting torn up just thinking about it.

Although the incident occurred years earlier, the emotion that quickly bubbled to the surface when retelling the story is indicative of both the depth and persistence of dignity injuries. By issuing a directive that knowingly placed employees in harm's way, management signalled that employees were valued only for their instrumental contributions and not for their inherent worth or humanity that extended beyond their job roles. As a whole, messages that revealed the instrumental-only orientation of the employment relationship were undignifying because they highlighted the hurtful truth that workers are hired as a means unto an end and therefore can be treated as substitutable and expendable.

In summary, social interactions and organizational practices that conceal workers' instrumentality are an important facet of remediated dignity. While participants expressed a desire for their instrumental value to be recognized and they implicitly understood that workplace relationships are fundamentally instrumental, they did not want to be reduced to only their instrumental value. This contradictory view of instrumentality gave rise to the intermittent salience of remediated dignity. That is, when employees' instrumental value was high and when their security needs were met, instrumental relationships were largely backgrounded and injuries subsided. But 
when their instrumental worth was questioned or when their work relationship was precarious, injuries of instrumentality surfaced, calling for remediation. Therefore, concealing instrumentality remediated workplace injuries and was perceived as affirming. In contrast, revealing instrumentality - whether it had the effect of creating new injuries or exacerbating existing ones - was highly undignifying.

Remediation of inequality. The second workplace injury that calls for remediation is inequality. As described above, equality is an important dignity need - yet one that systematically can be denied by organizational structures. Employees expressed appreciation for affirming interactions that drew attention away from inequalities. Dignity affirmations included messages that concealed the unequal nature of work, including any kind of message that communicated equality. For instance, a blue-collar worker reflected positively on an experience he had at a previous job:

I'd say when I got treated with dignity it would probably be like from my higher-up, like when I was welding, and it made me feel like more of an equal than a subordinate. Made me feel better about my job, you know, morale-wise. It makes you feel like they actually notice you. You're just not a number in the workforce, you know. They called me by my first name, just introduced me to some of the other office people, took me out for lunch, you know. But, yeah, it felt good, you know. It's something that's like an experience money can't buy.

Similarly, a clerk at a financial organization addressed the dignity affirming effect of having high-ranking officials treat him and his coworkers as equals:

Once a year we have a company meeting and the CEO comes and talks to us along with a lot of the other, you know, higher up people. And even though they're ultrarich and really smart, the way that they talk to us is just, you know, treat us like equals and just explain things so everybody can understand and give us a chance to answer questions, to ask questions.

In contrast, drawing attention to someone's subordinated position was viewed as extremely harmful to dignity. Denials included social interactions and organizational practices that revealed inequality, such as being talked to as a second-class citizen, gratuitous highlighting of status differences, and treatment of people in lower positions with lower levels of respect. A secretary felt her company had a culture of 'giving lipservice' to equality, saying, 'they make a lot of noise about saying that we're all a team and we're all equally important, but then their actions belie that'. She described:

Being treated with dignity comes down a lot to me with just being treated with common courtesy and, you know, saying please, and thank you, and excuse me if you're interrupting someone when they're working.... [Some of the managers] feel that your time is not as valuable as theirs. You know what I mean? You can be interrupted always and abruptly and without any, you know, even the semblance 
of 'excuse me'. For the most part the ones that were middle management or above would be extremely considerate of each other, but I was to be dumped on.

While she addressed a lack of general manners in her story (which could be viewed as a form of disrespectfulinteraction), it was the distribution of civility in her office that marked her time and space as less valuable than others. She particularly resented the lack of courtesy because she believed it communicated an assessment of her lesser value.

A common way people's value was dismissed was when status differences were highlighted in ways that made them feel undervalued and unappreciated. A woman who worked as a long-term temporary employee at a professional office was deeply hurt by status differences:

I don't know if anyone else in here has ever been a temp, but as a temp, you can feel very low amounts of dignity sometimes. It makes me think of The Office [television show], Ryan the temp. And he always was treated like total crap because he's the temp. And that's happened to me before. I remember this one specific time they were having like a fun day and all getting like free water bottles. And someone was like, 'Don't give them to the temps'. And they walked past my desk.

In summary, social interactions and organizational practices that conceal inequalities are the other essential component of remediated dignity. Participants expressed a strong desire to be treated as equal to salient others - whether bosses, peers, or customers. But when employees were on the lesser valued side of an unequal relationship, the remediated inequality component became salient. Furthermore, the more asymmetrical inequalities were, the deeper the injuries that were experienced. Although concealing efforts typically did little, if anything, to change the fundamental conditions of inequality (whether affecting pay, power, or status), they were experienced as affirming. Conversely, highlighting inequalities was perceived as gratuitous and highly undignifying.

At first glance, affirmations of remediated instrumentality and remediated inequality look much like respectful interaction. But moving beyond the surface level (and particularly when taking denials into consideration), remediated dignity operates in ways that clearly distinguish it from inherent dignity. As a whole, remediated dignity reflects a dependence upon others to mitigate injuries of instrumentality and inequality. Participants were well aware that within the employment context, they were valued primarily for their instrumental contributions and, for lower ranked and lower status employees, that their relative worth was less than others in the organization. When others drew attention to those conditions, it exacerbated their injuries. The more marginalized individuals were in terms of inequality and instrumentality, the more prominently remediated dignity played into their workplace experience. Conversely, when people were more advantaged within an organization - whether by power, status, job security, and so forth - injuries to dignity were much smaller, thereby lessening, if not eliminating, their need for remediated dignity. 


\section{DISCUSSION}

By privileging the perspectives of working adults, this study begins to fill important empirical gaps in the literature and offers theoretical insights into the phenomenon of workplace dignity. Specifically, I identified a range of experiences and desires reflecting both dignity and indignity at work. Participants' stories revealed three primary components by which dignity is affirmed and denied. Framed in positive terms, these include inherent dignity as recognized by respectful interaction, earned dignity as recognized by messages of competence and contribution, and remediated dignity as recognized by social interactions and organizational practices that conceal the instrumental and unequal nature of the workplace. The theoretical contributions of this research are described below.

\section{Theoretical Contributions}

The primary contribution of this research is that it points to the existence of three primary components of dignity, each with a unique locus of human value. Two of these components align with previously theorized meanings of dignity: inherent dignity as godgiven and earned dignity as self-generated (Brennan and Lo, 2007; Hodson, 2001). The third component, which I term remediated dignity, is an other-dependent dignity. To explain, remediated dignity is a negatively-valenced component that is tightly coupled with the instrumental and unequal workplace context. As individuals' sense of self-worth and self-value is undermined by instrumental-only valuations and inequalities embedded in the employment relationship, they become dependent upon others to remedy those workplace dignity injuries by concealing hurtful truths of working life. Likewise, they are vulnerable to others who (intentionally or unintentionally) may inflict greater injury by revealing their instrumentality and inequality. Together, these three dignity components provide a more complete account of the experience of workplace dignity than was previously offered by empirical research. Additionally, deeper interrogation of the components reveals several insights that extend workplace dignity theory.

The first theoretical insight is that affirmations and denials of dignity typically are experienced through communicative interactions. Regardless of the source of dignity - godgranted, self-generated, or other-dependent - what ultimately affirms or denies those dignities is interaction with others. Previous theorizing had acknowledged that communication played an important role in inherent dignity and the desire for respectful relations. For instance, Sayer (2007) asserted that one's experience of dignity relies upon 'words and deeds', as respectful communication recognizes another person as 'someone who is more than what they do for a living, who demands respect simply as a person' (p. 572; see also Bolton, 2007; Hodson, 2001). Additionally, numerous empirical studies noted violations of human dignity that arose from rude or disrespectful interaction (e.g., Apostolidis, 2005; Baker, 2014; Cleaveland, 2005). The current study extends this original thinking by revealing that communication is not limited to meeting desires for respectful interaction associated with inherent dignity, but instead plays an equally prominent role in the earned and remediated components. To explain, earned dignity is grounded, in large part, in individuals' efforts 
and abilities. However, simply being competent or making a contribution is not sufficient to experience a dignity affirmation. Instead, individuals also must have their instrumental contributions recognized through affirming communication. Alternatively, when individuals engage in communicative interactions that dismiss or demean their competence and contributions, they experience dignity violations. Therefore, communication is fundamental to the experience of earned dignity.

Similarly, while remediated dignity is grounded in workplace injuries stemming from the material and structural conditions of the employment relationship, the immediate experience of dignity is communicatively bound. For instance, conditions such as power imbalances (Fleming, 2005), job insecurities (Stuesse, 2010), control systems (Crowley, 2012), labour markets (Dufur and Feinberg, 2007), organizational structures (Lucas et al., 2013), and so forth have been shown to be the basis of inequalities and instrumentalities that lead to dignity injuries. Yet, these deep structural conditions often remain invisible to employees. In contrast, the resultant communication - whether it is abusive supervision, demeaning interactions, exploitative encounters, or symbolic expressions of inequality - is immediately recognizable. Put another way, communication can be viewed as the tangible expression of problematic workplace structures. Fortunately, affirming communication that compensates for and/or conceals problematic inequalities and instrumentalities can offset those injuries. As such, dignity injuries are exacerbated or remediated through communication with others.

A second theoretical insight is that that there are important internal tensions that further complicate the achievement of dignity. Stohl and Cheney (2001) described how organizational tensions - which they broadly define as a clash of ideas, principles, or actions - can impede efforts towards more employee-centred organizing. While organizational tensions, including paradoxes and contradictions, may not be immediately visible (if visible at all) in lived experience, they can be foregrounded by theoretical interrogation. One important tension of workplace dignity is a contradiction embedded in expectations of earned and inherent dignity. Specifically, the earned dignity component appears to be aggravated within lived experience by equality expectations carried forward from the inherent dignity component. Inherent dignity starts from a position that everyone is entitled to a full, equal, and unconditional valuation; in contrast, earned dignity has a conditional quality in that dignity is gained by individual actions and merits (Brennan and Lo, 2007; Hodson, 2001). Yet, while participants acknowledged their instrumental value is indeed conditional in affirmative situations (i.e., people can be deserving of a higher valuation due to their instrumental contributions), implicit in their accounts was a resistance to the corollary relationship that necessarily exists in negative situations (i.e., people also can be deserving of a lower valuation due to smaller or nonexistent instrumental contributions). In cases of the latter, when individuals found themselves in the negative situation of realizing their conditional and variable value was less than others, a dignity threat was experienced (see also Khademi et al., 2012; Lucas, 2011). Individuals drawing upon expectations of inherent dignity to evaluate their experiences of earned dignity points to an important practical problem - namely, while meanings of different dignities may be theoretically distinct, they remain tangled in lived experience. 
Another important tension of workplace dignity is a paradox exposed by comparing earned and remediated dignity components. On the one hand, messages acknowledging competence and contribution are highly dignifying. Praise for a job well done, compliments, and sincere appreciation for the quality of work performed affirm the instrumental value of individuals and, in turn, raise their earned dignity. On the other hand, messages that reveal rather than conceal the instrumental workplace relationship are highly undignifying and exacerbate dignity injuries. Together, these expectations present a paradox as workers' instrumental value must be acknowledged in order to achieve earned dignity, but simultaneously must be concealed to protect their remediated dignity injuries. Because of this paradox, it becomes even more difficult for people to feel fully dignified at work and for organizations to bolster employees' dignity, as social interactions and organizational practices cannot simultaneously conceal and reveal instrumental valuations.

A third theoretical insight is that this research demonstrates the centrality of instrumental valuations in experiencing workplace dignity. Across theoretical traditions, inherent dignity has been positioned as the ultimate value (e.g., Dierksmeier, 2011; Islam, 2012). Moreover, empirical research has focused on violations of inherent dignity through dehumanization and reification (e.g., Doherty, 2011; Dufur and Feinberg, 2007). Even participants initially defined dignity as 'being treated like a human' and spoke at length about respectful interaction. Yet, in their stories of dignity affirmations, they frequently described events linked to evaluations of their instrumental worth. It was messages that acknowledged their instrumental contributions, and not their inherent worth as a human, that were the basis of many affirmations. As such, earned dignity appears to play a more central role in workplace dignity than previously theorized. Whether this valuation is due to a desire to differentiate oneself from others, or to privilege the worth associated with a more contextually-salient 'worker' role, this insight challenges conventional thinking by suggesting the possibility that in certain contexts human dignity may be subordinated to other dignity components.

Overall, the expressed need for remediation of workplace injuries, the centrality of communication in the experience of dignity, the tensions embedded within various dignity components, and the importance of instrumental valuations in experiencing affirmations of dignity suggest that workplace dignity is theoretically distinct from human dignity. That is, dignity at work is not solely about having one's inherent worth recognized in a particular context - or even that workplaces are contexts in which dignity is harder to achieve. Instead, the very nature of the employment relationship fundamentally changes people's orientation towards what it means to have dignity at work. Specifically, experiencing workplace dignity requires employees to negotiate competing views of dignity: entitlement, in which they protect the dignity that is inherent to their humanity; self-sufficiency, by which they promote their dignity and value through their actions; and dependence, by which they (struggle to) accept that their dignity is vulnerable to others. Employees also must negotiate competing views of the employment relationship, whereby they sometimes resist its unequal and instrumental nature and at other times find ways to use that relationship to their advantage. Moreover, because employees can experience dignity despite problematic conditions of the employment relationship, core assumptions about dignity are challenged. In particular, while equality and non-instrumental valuations are positioned as 
the very essence of human dignity, they apparently are not absolute requirements for achieving workplace dignity. In other words, employees and employers have found ways to affirm individuals' dignity at work even when, theoretically, human dignity should not be possible in the workplace context. For these reasons, workplace dignity is a complex phenomenon that is theoretically distinct from basic human dignity.

\section{Critical Questions of Practicality}

Based on the findings, it is tempting to offer practical suggestions for improving dignity in the workplace. However, it is unlikely that truly novel suggestions could be made. In fact, Bolton (2013) says, 'Very recent prescriptions from high-profile management gurus mirror early human relations writings and call for management practice to create the conditions for dignity at work' (p. 163). Even absent novel suggestions, the fact that indignity remains a significant concern in modern organizations indicates that conventional management prescriptions are either ineffective or difficult to implement and/or sustain. Speaking to this concern, Karlsson (2012) explains that knowing what constitutes dignity at work is not sufficient for creating dignified workplaces. He says, 'If the demands of dignified work were entirely compatible with employer interests, such knowledge and policies of dignity would not be necessary' (p. 6). Therefore, I take a different tack. Specifically, I identify three clusters of conventional suggestions tied to each component of workplace dignity and then raise critical concerns about their feasibility or potential effectiveness. This critique is not to dissuade organizations from making strides in improving dignity, but instead to draw attention to why achieving workplace dignity is anything but easy.

A first set of suggestions centres on better acknowledging employees' inherent dignity through respectful interaction in the workplace. This includes a range of options from investing in company-wide sensitivity training, to instituting a range of bullying and harassment policies, to making civility and 'niceness' part of the performance review process to ensure that dignifying interactions are rewarded and undignifying interactions are disciplined. While there may be some benefit to improving an organization's culture of dignity, it can in effect be replacing one set of problems with another. Primarily, there are questions and concerns raised regarding whether respectful interactions are motivated by genuine concern for others. If organizational members are compelled to 'manufacture' respectful interactions, individuals on the receiving end of those interactions likely will not be affirmed in their dignity, but instead will recognize the obligatory nature of such pleasantries and view them as patronizing or disingenuous, further exacerbating dignity injuries. Correspondingly, 'being nice' imposes significant emotion labour burdens on people, especially in high-stress contexts. Finally, too much focus on individual dignity may heighten employee sensitivity to dignity threats, resulting in even minor slights being viewed negatively.

A second set of suggestions deals with enhancing the earned dignity of employees by boosting their competence and contribution and boosting recognition of their performance. Suggestions in this vein include investing in specialized training courses, tuition reimbursement for advanced education, more robust on-the-job training, and internal mentorship programmes. It also includes offering more special recognition 
programmes to reward employees for their contributions - from formal reward programmes to peer recognition systems. And it involves paying more careful attention to how discipline and corrective feedback are delivered. Again, there are critical questions raised by these efforts. All of these concerns are embedded in larger tensions between balancing the need to accomplish work goals (without downgrading quality standards or performance expectations) versus caring for individuals who perform the work. One issue concerns the extent to which it is the responsibility of organizations to train employees beyond their immediate job roles or to groom individuals for promotion. Providing too much training - especially when better jobs are not available within an internal labour market - may be a poor investment of resources and may lead to a more dissatisfied and undignified workforce if they perceive they must work 'below their level'. There are additional concerns about demotivating strong performers and diminishing the value of recognition if recognition is granted to many instead of earned by a few. Finally, despite efforts to build competence, it is a fact of organizational life that not all employees are competent in their particular roles. People are placed in positions beyond their skill level, make mistakes, withhold their best efforts, or otherwise fail to make positive contributions to organizational goals. In terms of dealing with gentle corrections, having a dignity-centred focus on delivering feedback may counteract the perceived seriousness of corrections, resulting in neither remedying poor performance nor curtailing problematic behaviours.

A third set of suggestions centres on offering remediated dignity by making concerted efforts to conceal injuries of instrumentality and inequality. Practical applications for this approach involve paying closer attention to unintended consequences of certain interactions and organizational practices with regard to effects they may have on exacerbating dignity injuries. Specifically, these include limiting certain practices that highlight inequality (e.g., practices of addressing supervisors with honorific titles and subordinates by first name, excluding lower-ranking employees from company events) and instrumentality (e.g., calling people by employee number instead of name, using fear tactics of expendability as a motivator for performance), and may even go as far as to express equality (e.g., explicitly and regularly telling employees that 'everyone is an equally important part of the team') and non-instrumental valuation (e.g., celebrating individuals and their non-work related life events). While these kinds of concealing practices can remediate dignity injuries, they alternatively can be viewed as a form of systematically distorted communication. That is, if management becomes so successful at concealing instrumentality and inequality that workers no longer see problematic structures and power relations, it may cause more long-term harm than good. Research has shown when dignity is violated, individuals can engage in practices of resistance to reclaim not only a sense of worth but the material resources to affirm their worth (Hodson, 2001; Karlsson, 2012; Roscigno and Hodson, 2004). Perhaps it is best that not all inequality and instrumentality is concealed so there will be motivation for workers to engage in productive acts of resistance.

\section{Limitations and Future Directions}

As with all research, this study has limitations. While the purpose of this study was to gain theoretical insight and not to make empirical generalizations, it still is worth 
noting that there was some bias in the sample of participants. The primary source for recruitment was newspaper classified advertisements. Therefore, participants tended to be concentrated in lower-level occupations and/or were current job seekers. On the one hand, this sample could be viewed as a strength because it brought in a large pool of service workers who previously have been understudied in organizational research. Additionally, their lower occupational statuses potentially raised unique issues of workplace dignity related to social stigma and class-based differences that otherwise might have been missed. On the other hand, it could be viewed as a weakness in that there were no executives or upper-level managers in the sample. For example, the strong desire for equality as a signal of dignity could alternatively be viewed by those higher in an organizational hierarchy as disregard for authority. For better or worse, the themes of workplace dignity were influenced by the types of workers represented in the sample. Future research could tap into understandings of dignity from upper-level management or high-status profession standpoints (e.g., medical doctors, attorneys).

Second, gender differences were largely silenced in the focus groups. All but two focus groups were either all-male or mixed-sex groups. In these situations, women voiced few concerns about sexual harassment and/or discrimination. In contrast, in the two all-female groups, gender was discussed with much passion and emotion. The women talked candidly about the multiple ways sex and gender impacted their ability to achieve dignity at work. Had there been more same-sex groups, it may have allowed for more detailed analysis of gender differences. Exploring gendered differences in workplace dignity (as well as class, race, sexuality, and other forms of difference) is an important avenue for future research.

Third, this study did not account for participants' role in creating indignity at work. Dignity and indignity can begin anywhere in an organization, meaning employees are not simply passive recipients but also agents who can build or destroy dignity. In fact, employees whose pathways to dignity are blocked at work may in turn (perhaps not even intentionally) be the very people who are destroying the experience of dignity for coworkers, superiors, and subordinates during their shifts and/or causing incursions on the dignity of other organizations' employees outside of work (e.g., restaurant servers, cashiers). Moreover, it was assumed that all workers were competent and deserving of high instrumental valuations. Yet, it is possible that some participants may not be putting forth any good faith efforts to perform well in their respective job roles. But because these focus groups were designed to privilege the perspectives and experiences of participants, it could not be determined if participants themselves also were perpetrators of verbal abuse and disrespectful interactions or if they were incompetent in their respective job roles. Therefore, a more holistic look at various workplaces and organizational members' behaviours would be necessary to account more fully for individuals' roles in and responsibilities for constructing (in)dignities on the job.

Finally, my role as a researcher introduced some bias. As someone interested in and sympathetic to issues of dignity at work, I encouraged individuals to speak freely about indignities they have experienced. Moreover, as a researcher whose objective was to privilege workers' stories (versus a manager whose purpose would be to resolve 
work issues), I resisted my occasional scepticism and did not challenge participants who presented stories that, under different conditions, I might have viewed as unreasonable complaining. Additionally, my positionality as a researcher who has studied social class issues further influenced data collection and interpretation. While it was not my intention to foreground social class, my implicit orientation to class-based issues may have impacted the extent to which I was able to recognize concerns regarding inequality and then ask follow-up probes to elicit further detail.

Apart from research that addresses limitations, further research is necessary to deepen our collective understanding of dignity at work. Future studies could answer a range of important questions: What is the relationship between dignity and related phenomena (e.g., bullying, stigma, organizational injustice)? What organizational (e.g., counterproductive work behaviours, productivity, engagement) and individual (e.g., employee health, emotional wellbeing) outcomes are linked to dignity? Are organizations that make dignity an explicit part of their mission, vision, and values more likely to be perceived by employees as a dignified place to work? Do organizations with cultures of dignity perform better than their competitors?

\section{CONCLUSION}

Workplace dignity is important to workers, as they possess a strong desire to derive a sense of self-worth from their work and to be treated respectfully. But, workplaces are full of challenges for experiencing dignity. On the one hand, work is a place where people can build a sense of dignity by making important contributions, developing their personal competence, and being recognized as a valuable part of a larger whole. On the other hand, it is a place where dignity can be destroyed by disrespect, dehumanization, or disposability. Moreover, their dignity - whether inherent, earned, or remediated - is typically affirmed or threatened by communicative interactions with salient organizational others. Therefore, researchers and managers alike should continue to make concerted efforts to learn more about what constitutes (un)dignified work experiences and how to communicate in ways that can facilitate more dignity for workers.

\section{REFERENCES}

Alvesson, M. and Deetz, S. (2000). Doing Critical Management Research. London: Sage.

Apostolidis, P. (2005). 'Hegemony and hamburger: migration narratives and democratic unionism among Mexican meatpackers in the U.S. west'. Political Research Quarterly, 58, 647-58.

Ashforth, B. E., Kreiner, G. E., Clark, M. A. and Fugate, M. (2007). 'Normalizing dirty work: managerial tactics for countering occupational taint'. Academy of Management Journal, 50, 149-74.

Baker, S. J. (2014). You Bring Yourself to Work: An Exploration LGB/TQ Experiences of (In)Dignity and Identity. Unpublished PhD Dissertation, University of Nebraska-Lincoln.

Belanger, J. and Edwards, P. (2013). 'The nature of front-line service work: distinctive features and continuity in the employment relationship'. Work, Employment \& Society, 27, 433-50.

Bolton, S. C. (2007). 'Dignity in and at work: why it matters'. In Bolton, S. C. (Ed.), Dimensions of Dignity at Work. Oxford: Butterworth-Heinemann, 3-16.

Bolton, S. C. (2010). 'Being human: dignity of labor as the foundation for the spirit-work connection'. Journal of Management, Spirituality, and Religion, 7, 157-72. 
Bolton, S. C. (2013). 'Dignity'. In Smith, V. (Ed.), Sociology of Work: An Encyclopedia (Vol. 1). Thousand Oaks, CA: Sage, 163-66.

Bolton, S. C. and Laaser, K. (2013). 'Work, employment and society through the lens of moral economy'. Work, Employment \& Society, 27, 508-25.

Brennan, A. and Lo, Y. S. (2007). 'Two conceptions of dignity: honour and self-determination'. In Malapss, J. and Lickiss, N. (Eds), Perspectives on Human Dignity: A Conversation. Dordrecht: Springer, 43-58.

Castel, R. (1996). 'Work and usefulness to the world'. International Labour Review, 135, 615-22.

Chiappetta-Swanson, C. (2005). 'Dignity and dirty work: nurses' experiences in managing genetic termination for fetal anomaly'. Qualitative Sociology, 28, 93-116.

Cleaveland, C. (2005). 'A desperate means to dignity: work refusal amongst Philadelphia welfare recipients'. Ethnography, 6, 35-60.

Creswell, J. W. (2007). Qualitative Inquiry and Research Design: Choosing Among Five Approaches. Thousand Oaks, CA: Sage.

Crowley, M. (2012). 'Control and dignity in professional, manual and service-sector employment'. Organization Studies, 33, 1383-406.

Dempsey, S. E. and Sanders, M. L. (2010). ‘Meaningful work? Nonprofit marketization and work/life imbalance in popular autobiographies of social entrepreneurship'. Organization, 17, 437-59.

Dierksmeier, C. (2011). 'Reorienting management education: from homo oeconomicus to human dignity'. In Amann, W., Pirson, M., Dierkmeier, C., von Kimakowitz, E. and Spitzeck, H. (Eds), Business Schools Under Fire: Humanistic Management Education as the Way Forward. New York: Palgrave Macmillan, 19-40.

Doherty, E. M. (2011). 'Joking aside, insights to employee dignity in 'Dilbert' cartoons: the value of comic art in understanding the employer-employee relationship'. Journal of Management Inquiry, 20, 286-301.

Dufur, M. J. and Feinberg, S. L. (2007). 'Artificially restricted labor markets and worker dignity in professional football'. Journal of Contemporary Ethnography, 36, 505-36.

Finlay, W. W., Sartain, A. Q. and Tate, W. M. (1954). Human Behavior in Industry. New York: McGraw-Hill.

Fleming, P. (2005). “Kindergarten cop”: paternalism and resistance in a high-commitment workplace'. Journal of Management Studies, 42, 1469-89.

Garrison, K. (1952). 'The worker's morale'. In Gray, J. S. (Ed.), Psychology in Industry. New York: McGraw-Hill, 315-47.

Gioia, D. A. and Pitre, E. (1990). 'Multiparadigm perspectives on theory building'. Academy of Management Review, 15, 584-602.

Gunn, A. M. (2011). 'The discursive construction of care when there is no care to be found: organizational life (re)framed by those on the socio-economic margins facing job loss'. Culture \& Organization, 17, 65-85.

Hodson, R. (2001). Dignity at Work. Cambridge, UK: Cambridge University Press.

Islam, G. (2012). 'Recognition, reification, and practices of forgetting: ethical implications of human resource management'. Journal of Business Ethics, 111, 37-48.

Kamberelis, G. and Dimitriadis, G. (2005). 'Focus groups: strategic articulations of pedagogy, politics, and inquiry'. In Denzin, N. K. and Lincoln, Y. S. (Eds), Sage Handbook of Qualitative Research, 3rd edition. Thousand Oaks, CA: Sage, 887-907.

Karlsson, J. C. (2012). Organizational Misbehaviour: Narratives of Dignity and Resistance. London: Palgrave Macmillan.

Kensbock, S., Jennings, G., Bailey, J. and Patiar, A. (2014). 'Distinction work and its consequences for women working as room attendants within five star hotels on the Gold Coast, Australia'. Hospitality \& Society, 4, $55-73$.

Khademi, M., Mohammadi, E. and Vanaki, Z. (2012). 'Nurses' experiences of violation of their dignity'. Nursing Ethics, 19, 328-40.

Lee, M. Y. K. (2008). 'Universal human dignity: some reflections in the Asian context'. Asian Journal of Comparative Law, 3, 283-313.

Lindlof, T. R. and Taylor, B. C. (2011). Qualitative Communication Research Methods, 3rd edition. Thousand Oaks, CA: Sage.

Lucas, K. (2011). 'Blue-collar discourses of workplace dignity: using outgroup comparisons to construct positive identities'. Management Communication Quarterly, 25, 353-74. 
Lucas, K. and Gist, A. N. (2015). 'Organizing social class: implications for working-class dignity'. Paper presented at the Academy of Management annual meeting, Vancouver, BC, 10 August 2015.

Lucas, K., Kang, D. and Li, Z. (2013). 'Workplace dignity in a total institution: examining the experiences of Foxconn's migrant workforce'. Journal of Business Ethics, 114, 91-106.

Lutgen-Sandvik, P., Tracy, S. J. and Alberts, J. K. (2007). 'Burned by bullying in the American workplace: prevalence, perception, degree and impact'. Journal of Management Studies, 44, 837-62.

Mears, A. and Finlay, W. (2005). 'Not just a paper doll: how models manage bodily capital and why they perform emotional labor'. Journal of Contemporary Ethnography, 34, 317-43.

Miles, M. B., Huberman, A. M. and Saldana, J. (2014). Qualitative Data Analysis: A Methods Sourcebook, 3rd edition. Thousand Oaks, CA: Sage.

Morgan, D. L. (1997). Focus Groups as Qualitative Research. Thousand Oaks, CA: Sage.

Newman, K. S. (1999). No Shame in my Game: The Working Poor in the Inner City. New York: Russell Sage Foundation.

Otis, E. M. (2008). 'The dignity of working women: service, sex, and the labor politics of localization in China's City of Eternal Spring'. American Behavioral Scientist, 52, 356-76.

Patient, D. L. and Skarlicki, D. P. (2010). 'Increasing interpersonal and informational justice when communicating negative news: the role of the manager's empathic concern and moral development'. Journal of Management, 36, 555-78.

Pearson, C. M. and Porath, C. L. (2005). 'On the nature, consequences and remedies of workplace incivility: no time for "nice"? Think again'. Academy of Management Executive, 19, 7-18.

Pierce, J. L. and Gardner, D. G. (2004). 'Self-esteem within the work and organizational context: a review of the organization-based self-esteem literature'. Journal of Management, 30, 591-622.

Purser, G. (2009). 'The dignity of job-seeking men: boundary work among immigrant day laborers'. Journal of Contemporary Ethnography, 38, 117-39.

Roscigno, V. J. and Hodson, R. (2004). 'The organizational and social foundations of worker resistance'. American Sociological Review, 69, 14-39.

Sayer, A. (2007). 'Dignity at work: broadening the agenda'. Organization, 14, 565-81.

Sayer, A. (2009). 'Contributive justice and meaningful work'. Res Publica, 15, 1-16.

Sayer, A. (2011). Why Things Matter to People: Social Science, Values and Ethical Life. Cambridge, UK: Cambridge University Press.

Stacey, C. L. (2005). 'Finding dignity in dirty work: the constraints and rewards of low-wage home care labour'. Sociology of Health \& Illness, 27, 831-54.

Stohl, C. and Cheney, G. (2001). 'Participatory process/paradoxical practices: communication and the dilemmas of organizational democracy'. Management Communication Quarterly, 14, 349-407.

Stuesse, A. C. (2010). 'What's "justice and dignity" got to do with it? Migrant vulnerability, corporate complicity, and the state'. Human Organization, 69, 19-30.

Tablan, F. (2015). 'Catholic social teachings: toward a meaningful work'. Journal of Business Ethics, 128, 291303.

Tepper, B. J., Moss, S. E., Lockhart, D. E. and Carr, J. C. (2007). 'Abusive supervision, upward maintenance communication, and subordinates' psychological distress'. Academy of Management Journal, 50, 116980.

Thompson, P. (2013). 'Financialization and the workplace: extending and applying the disconnected capitalism thesis'. Work, Employment \& Society, 27, 472-88.

Tracy, S. J. (2012). 'The toxic and mythical combination of a deductive writing logic for inductive qualitative research'. Qualitative Communication Research, 1, 109-42.

Tracy, S. J. (2013). Qualitative Research Methods: Collecting Evidence, Crafting Analysis, Communicating Impact. Hoboken, NJ: Wiley-Blackwell. 